\title{
Faire face à la souffrance. La crise des réfugiés en photos
}

Entretien avec Louisa Gouliamaki, photojournaliste, réalisé par Anastassia Tsoukala

Confronting Suffering: The Refugee Crisis Seen through Photos. An Interview with photojournalist Louisa Gouliamaki, carried out by Anatassia Tsoukala

Louisa Gouliamaki et Anastassia Tsoukala

\section{(2) OpenEdition}

\section{Édition électronique}

URL : https://journals.openedition.org/conflits/20451

DOI : 10.4000/conflits.20451

ISSN : $1777-5345$

Éditeur :

CECLS - Centre d'études sur les conflits - Liberté et sécurité, L'Harmattan

\section{Édition imprimée}

Date de publication : 10 octobre 2018

Pagination : 181-199

ISBN : 978-2-343-16812-8

ISSN : 1157-996X

Référence électronique

Louisa Gouliamaki et Anastassia Tsoukala, «Faire face à la souffrance. La crise des réfugiés en photos », Cultures \& Conflits [En ligne], 110-111 | été/automne 2018, mis en ligne le 10 octobre 2020, consulté le 06 janvier 2022. URL : http://journals.openedition.org/conflits/20451 ; DOI : https:// doi.org/10.4000/conflits.20451 


\title{
Faire face à la souffrance. La crise des réfugiés en photos
}

\author{
Entretien avec Louisa Gouliamaki, photojournaliste, \\ réalisé par Anastassia Tsoukala 1
}

Louisa Gouliamaki travaille comme photojournaliste depuis 1992. En 1996, elle assume la direction de la European Pressphoto Agency (EPA) à Athènes. En 19972000, elle couvre la crise dans les Balkans et le conflit au Kosovo; son travail est primé. Depuis 2005, elle collabore avec l'Agence France Presse (AFP). Son travail a été exposé en Grèce et à l'étranger. Il est visible sur son compte Instagram (Louisa.gouliamaki).

Anastassia Tsoukala est juriste et criminologue, Maître de Conférences HDR à l'Université Paris-Sud. Elle travaille sur la construction sociale de la menace, et sur les politiques de sécurité et les droits de l'homme en Europe. Champs cognitifs : immigration, lutte armée, violence des stades.

- Anastassia Tsonkala: L'actuelle crise des réfugiés, que tu as suivie de près puisque tu l'as couverte depuis 2015, a passé par plusieurs étapes, radicalement différentes les unes des autres. Quelles expériences, quelles images t'ont le plus marquée?

- Lonisa Gouliamaki: Je suis allée sur le terrain pour la première fois en juin 2015, sur l'île de Lesbos. Les arrivées de réfugiés étaient alors modérées, mais il n'y avait pas d'infrastructures d'accueil non plus. Les réfugiés, dont la majorité avait des enfants en bas âge, devaient se rendre au port pour se faire enregistrer. Le plus souvent, ils arrivaient sur des plages éloignées et devaient marcher pendant deux jours avant d'atteindre le port. C'était honteux. Je me rappelle, sur une plage, la police avait aligné les réfugiés qui venaient d'y arriver, les avait maintenus ainsi pendant un moment et, après, elle avait quitté les lieux sans leur fournir la moindre information. C'était à nous, photojournalistes, de répondre à toutes leurs questions. Nous avons dû tout assumer, allumer des feux de bois, leur expliquer ce qu'ils devaient faire pour aller au port, pour se faire enregistrer... Nous ne pouvions pas les transporter, c'était risqué

1. Entretien réalisé le 31 mai 2018 à Athènes. Traduit du grec par Anastassia Tsoukala. 
à l'époque, on pouvait être accusé de trafic de migrants. Nous savions qu'ils devraient marcher pendant des jours, les enfants dans les bras, alors qu'ils parlaient couramment l'anglais et qu'ils pouvaient facilement prendre un taxi, mais aucun chauffeur de taxi ne voulait d'eux, et nous ne pouvions rien faire d'autre pour eux. Nous savions aussi que les conditions d'enregistrement étaient exécrables, ils devraient faire la queue pendant des heures sous un soleil de plomb, sans avoir accès à des facilités sanitaires.

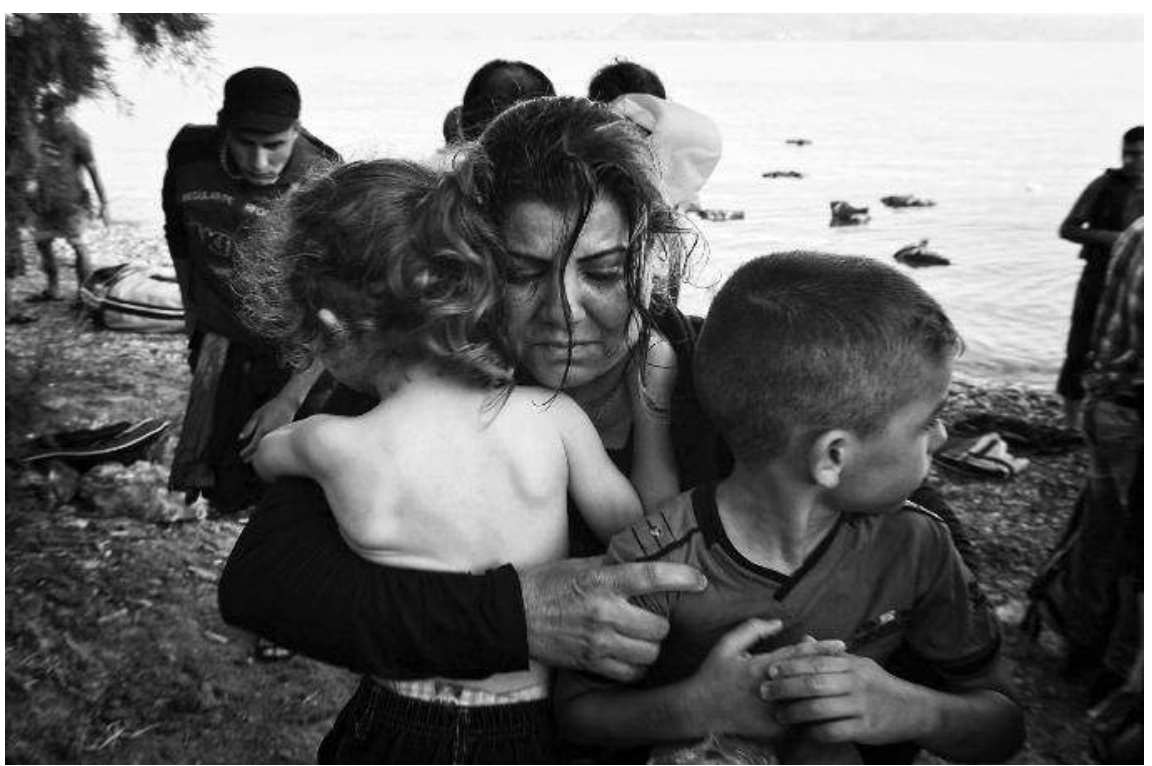

Une migrante syrienne serre ses enfants dans ses bras après leur arrivée, dans une embarcation surpeuplée, sur une plage près du port de l'île de Kos, le 15 août 2015. Le gouvernement grec a envoyé un ferryboat dans cette île touristique afin d'accélérer le processus d'enregistrement des centaines de réfugiés syriens, placés dans la zone portuaire le 14 août. Le ferry y restera pendant deux semaines, jusqu'à ce que les autorités enregistrent les nouveaux arrivants sur l'île, qui est déjà débordée par les réfugiés et les migrants.

(c) AFP PHOTO / LOUISA GOULIAMAKI

En août, je suis allée sur l'île de Cos. Là aussi, les arrivées étaient modérées mais, cette fois-ci, nous étions en face de réfugiés démunis qui, sans doute, avaient versé de faibles sommes d'argent aux trafiquants. Leurs embarcations avaient l'air de jouets gonflables, elles n'étaient certainement pas faites pour traverser la Mer Égée. Les moteurs étaient si petits que les carburants s'épuisaient au milieu de la traversée, les réfugiés devant continuer à la rame, alors que leurs embarcations commençaient à couler. Ils étaient tous très effrayés, plusieurs parmi eux faisaient la dernière partie du trajet à la nage. 
Au début, ils arrivaient au cours de la nuit. J'allais, avec des collègues, sur des endroits d'où on pouvait voir les côtes turques, on avait des jumelles et, si on distinguait une embarcation, ce qui était difficile car ils naviguaient sans lumière, nous allions les attendre sur la plage. Plus tard, ils arrivaient au cours de la journée, c'était moins risqué pour eux. En tout cas, faute d'infrastructures, ils dormaient tous n'importe où, on dressait des tentes partout, ce qui avait généré des réactions hostiles de la part de la population locale, qui se sentait menacée dans ses intérêts économiques en pleine saison touristique, bien que les réfugiés n'aient créé le moindre incident.

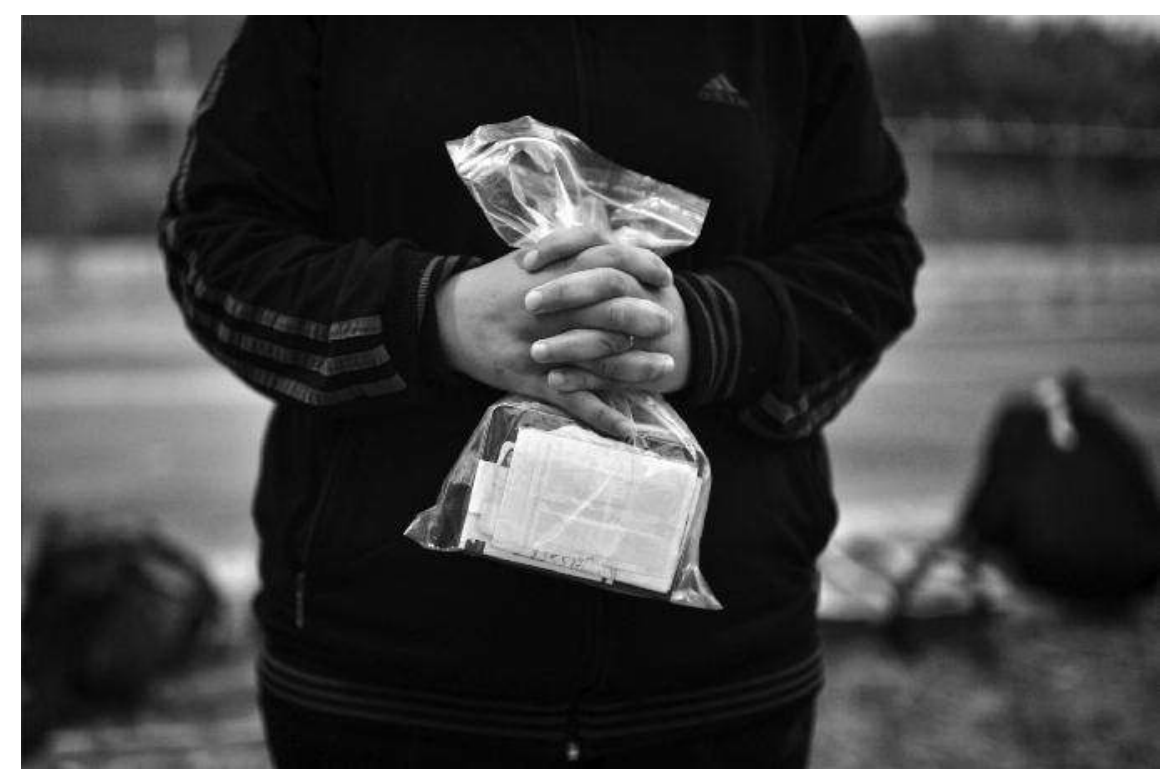

Un migrant syrien tient entre ses mains les passeports et des documents de famille après son arrivée sur l'île de Lesbos, le 18 juin 2015. À ce jour, près de 48000 réfugiés et migrants sont arrivés sur les côtes grecques, alors que le pays avait reçu 34000 personnes au cours de 2014, selon l'Organisation Internationale pour les Migrations.

(c) AFP PHOTO / LOUISA GOULIAMAKI photos?

- A. T. : Développais-tu un contact préalable ou prenais-tu directement des

- L. G. : Il y a toujours un contact, soit verbal, soit par des sourires ou des gestes. On peut prendre quelqu'un en photo sans son consentement si son visage n'est pas identifiable. Dans les autres cas, je rendais ma présence et ma caméra bien visibles pour qu'on puisse me faire comprendre, ne serait-ce que par des signes, qu'on ne voulait pas être pris en photo. Si je voyais une scène que je risquais de perdre, je tirais la photo et je cherchais à obtenir l'autorisa- 
tion postérieurement. D'autres fois, les gens pouvaient être réticents au début et, si je finissais par établir un certain contact avec eux, ils prenaient l'initiative et me demandaient que je les prenne en photo. J'ai eu quelques refus nets, surtout de la part des femmes qui refusaient pour des motifs religieux, et de la part d'hommes qui ne voulaient pas que leur épouse soit prise en photo et préféraient poser à leur place, en tenant eux-mêmes leurs enfants dans les bras.

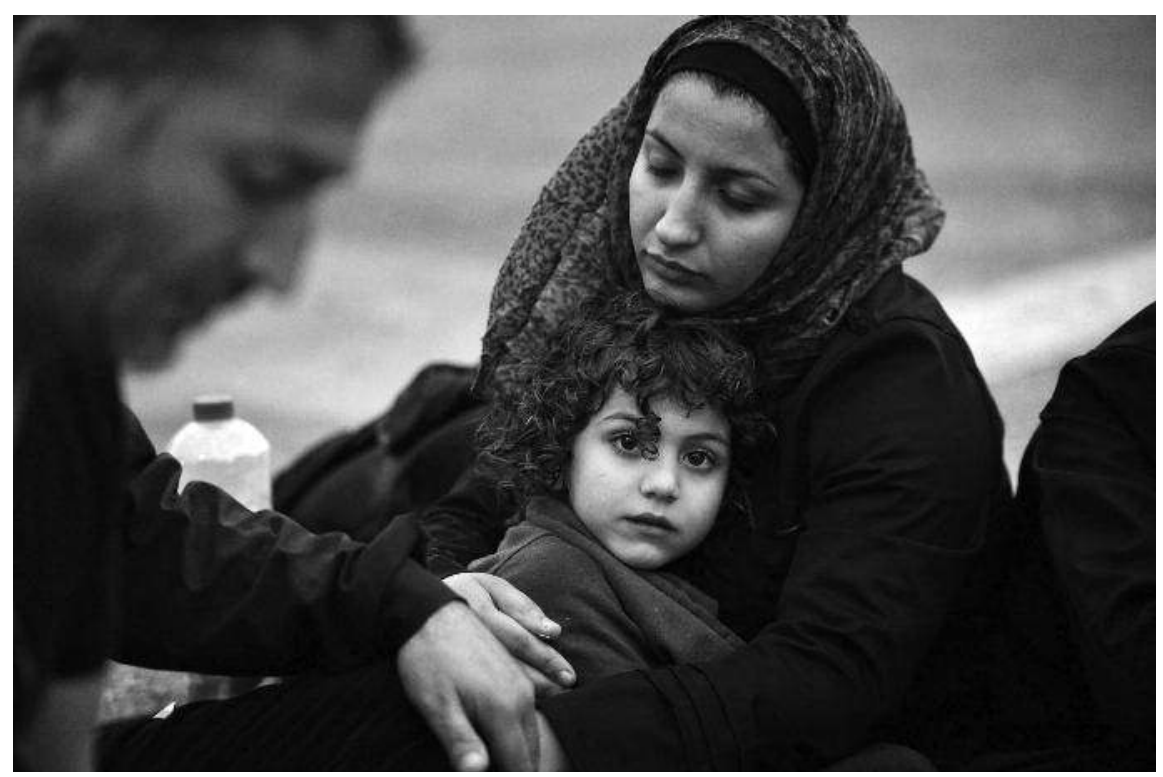

Une mère syrienne essaie de réchauffer sa fille après leur arrivée sur I'île de Lesbos, le 18 juin 2015.

(C) AFP PHOTO / LOUISA GOULIAMAKI

\section{- A. T. : Où les as-tu croisés à nouveau?}

- L. G. : En septembre, je couvrais le port du Pirée, l'un des lieux de rassemblement des réfugiés qui quittaient les îles pour arriver sur la Grèce continentale. Ils partaient tous vers le nord du pays, soit à pied soit en bus. Nous avons suivi leur itinéraire jusqu'en Hongrie. Ils arrivaient à Idomeni (passage frontalier entre la Grèce et la Macédoine) par tous les moyens possibles, en bus, en train, en taxi, à pied... De là, ils allaient en train jusqu'à la frontière serbo-hongroise. À partir de là, ils avançaient en marchant sur les rails du train mais, comme ils savaient que s'ils entraient en Hongrie en empruntant le passage frontalier, ils seraient enfermés dans des camps, ils essayaient d'y entrer en traversant des champs, en passant par-dessous des grillages... Ceux qui en avaient les moyens avaient recours à des trafiquants et se rendaient à la frontière austro-hongroise en taxi. 
Il m'est impossible d'oublier cette marche interminable, des gens en file, qui marchaient, marchaient, marchaient... d'Athènes à Idomeni, et de là à Belgrade, et plus loin, et plus loin encore, des familles, les enfants dans les bras, des jeunes, des vieillards, des blessés, des handicapés en fauteuil roulant... Ils traversaient tout un continent à pied. On ne peut pas se déplacer sur les rails du train quand on pousse une poussette ou qu'on est en fauteuil roulant, ils essayaient d'avancer en marchant à côté, il n'y avait pas suffisamment d'espace... Je les regardais et je me demandais sans cesse : pourquoi n'a-t-on pas mis en place un réseau d'assistance pour toutes ces personnes en détresse ?

- A. T. : Comment pouvais-tu tenir face à cette souffrance? Tu savais que beaucoup de ces gens-là avaient vu mourir ou avaient laissé derrière eux des membres de leur famille, des amis, des êtres qui leur étaient chers.

- L. G. : Plus les réfugiés étaient aisés et éduqués, plus ils protestaient, revendiquant un minimum d'infrastructures d'accueil. Mais dans la majorité des cas, les gens acceptaient tout de manière stoïque, ils ne se plaignaient guère, ils étaient motivés par l'espoir, ils étaient optimistes. Ils dégageaient une certaine joie, car ils avançaient, ils s'approchaient de leur destination finale puisque un grand nombre parmi eux avait de la famille en Europe. Certes, il y avait de la grogne, mais aussi beaucoup de sourires. Et puis, il y avait des enfants partout. Des enfants qui jouaient sans cesse, partout. Même quand ils étaient crevés de fatigue, ils jouaient, ils rigolaient entre eux, avec nous aussi. Cela nous faisait oublier leur souffrance, l'ambiance devenait légère.

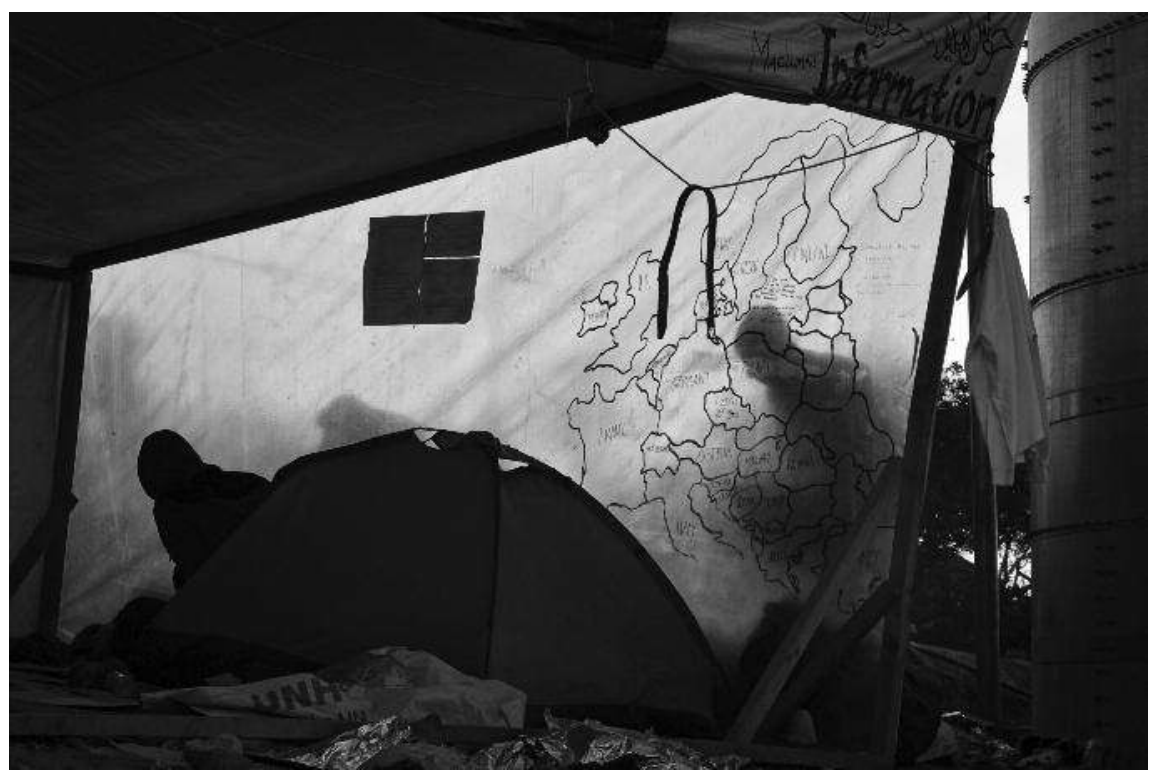

Des réfugiés et des migrants campent dans un ancien point d'informations, mis en place par une ONG à l'intérieur du camp surpeuplé de Moria, sur l'île de Lesbos, le 17 novembre 2015. 
À l'époque, il y avait beaucoup de monde rassemblé à Idomeni, mais ils traversaient la frontière rapidement, tout au plus au bout d'une demi-journée d'attente. Je me rappelle d'un grand groupe de Pakistanais, qui vivaient en Grèce sans papiers depuis 2004 et avaient saisi l'occasion pour quitter le pays sans se faire arrêter puisqu'ils étaient au chômage à cause de la crise financière. Je les voyais rire, insouciants, je pensais à cette façon qu'a la vie d'entremêler des histoires et des parcours humains, je réalisais à quel point les gens peuvent vivre différemment la même situation.

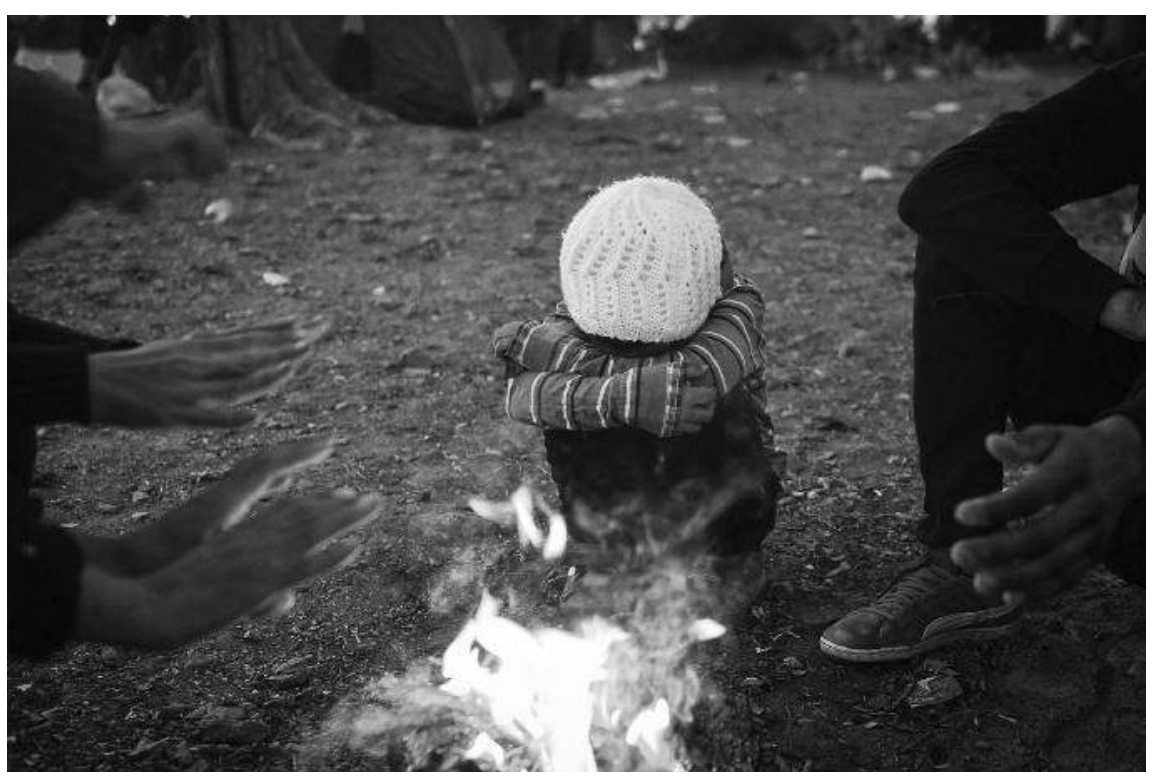

Une enfant réfugiée afghane tente de se réchauffer près d'un feu dans le camp de Moria, sur l'île de Lesbos, le 16 novembre 2015. Des réfugiés et des migrants attendent pendant des jours dans ce camp surpeuplé afin de se faire enregistrer et d'obtenir des documents temporaires qui leur permettront de poursuivre leur voyage.

(c) AFP PHOTO / LOUISA GOULIAMAKI met?

- A. T. : Que s'est-il passé quand les arrivées de réfugiés ont atteint le som-

- L. G. : J'étais alors à nouveau sur l'île de Lesbos, où on enregistrait en moyenne trente embarcations par jour. Les réfugiés, surtout des Syriens, arrivaient sans cesse sur des plages différentes, c'était de la folie, on ne savait pas où donner de la tête. On était abasourdi par le volume de nouveaux arrivants. Il y avait déjà eu des naufrages à cause des intempéries. On avait mis en place les premières infrastructures d'accueil, gérées par des ONG et des volontaires. Une fois enregistrés au port, les réfugiés étaient envoyés au centre d'accueil de Moria, où toutefois il n'y avait pas de place libre. De nombreuses familles, avec des enfants en bas âge, dormaient à la belle étoile privées de toute assis- 
tance matérielle, elles n'avaient même pas de couvertures. Au centre d'accueil de Kara-Tepe, les conditions étaient meilleures mais, quand il pleuvait, les tentes - des tentes d'été - devenaient inhabitables. Il était insupportable de voir toutes ces personnes qui avaient échappé à l'enfer souffrir de la sorte.

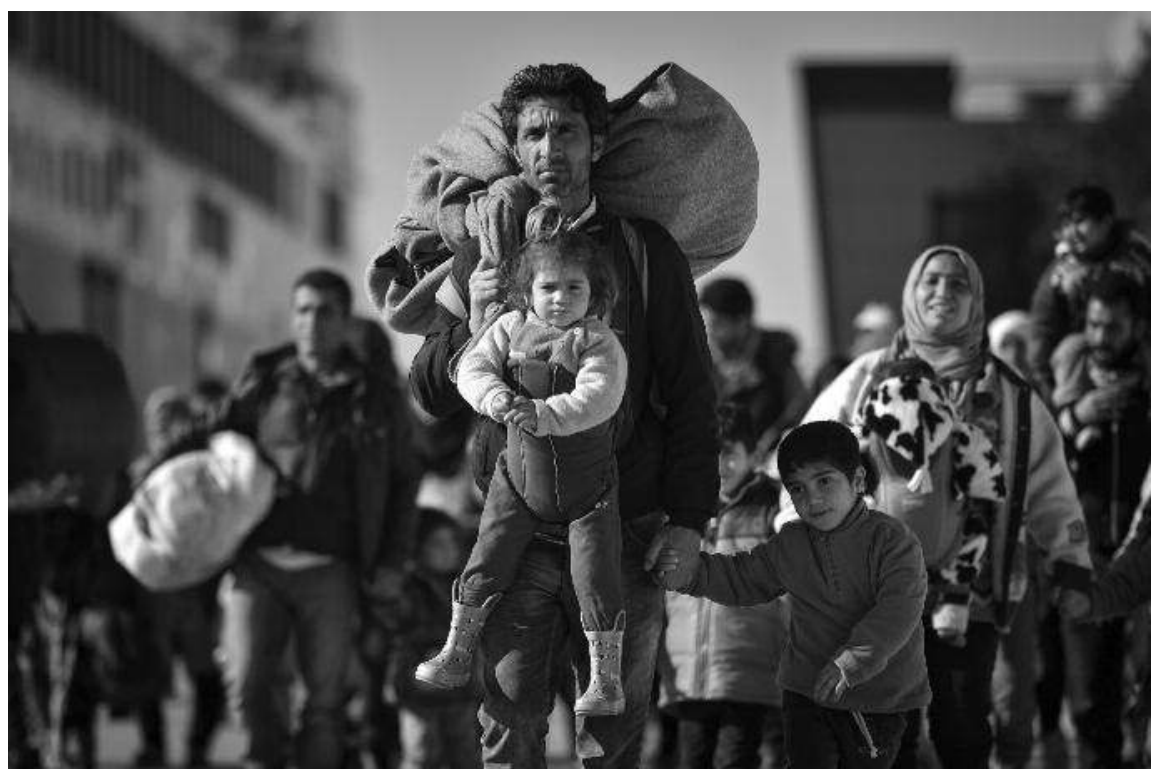

Des réfugiés marchent au long du port du Pirée, à peine arrivés des îles de Lesbos et de Chios, le 1er février 2016.

C AFP PHOTO / LOUISA GOULIAMAKI

En février 2016, il y avait près de 7000 réfugiés rassemblés à Idomeni. On avait commencé à fermer progressivement le passage frontalier, d'abord aux Maghrébins, ensuite aux Afghans et après aux Syriens de Damas, qui ne faisait pas partie de zones de guerre. Quand on a pratiquement fermé le passage frontalier, peu avant la conclusion de l'accord UE-Turquie, il y avait près de douze ou treize mille réfugiés campant de manière sauvage aux alentours. Il faisait froid, il pleuvait souvent; se déplacer au milieu de ce campement était hallucinant. Beaucoup de réfugiés essayaient de passer la frontière illégalement. Les conditions de vie y étaient exécrables et, pourtant, je préférais travailler là car je pouvais développer des contacts avec des réfugiés. Je visitais chaque jour quelques familles, on se disait bonjour, je leur demandais s'ils avaient besoin de quelque chose, on établissait un contact humain - ce qui était impossible aux îles où on les voyait juste passer - lequel, à son tour, créait des liens de confiance. Cela nous motivait à assumer d'autres rôles au-delà de notre métier. Je me rappelle d'une famille, on me fait de la pantomime, je comprends qu'il y a un problème de santé, on m'amène sous leur tente et je vois un homme visiblement malade. Ils n'étaient pas parvenus à communiquer avec les 
médecins car ils ne parlaient pas l'anglais, et le malade se trouvait dans un état critique. Je prends la boîte de son médicament, je la montre aux médecins, l'homme a été sauvé. Dans une autre famille, dont la mère venait d'accoucher, on me montre des yeux, de la lumière, je ne comprenais pas, je pensais que le nouveau-né avait des problèmes de vision, j'ai fini par trouver un interprète, ils avaient besoin d'une lampe de poche pour changer les lingettes du bébé durant la nuit.

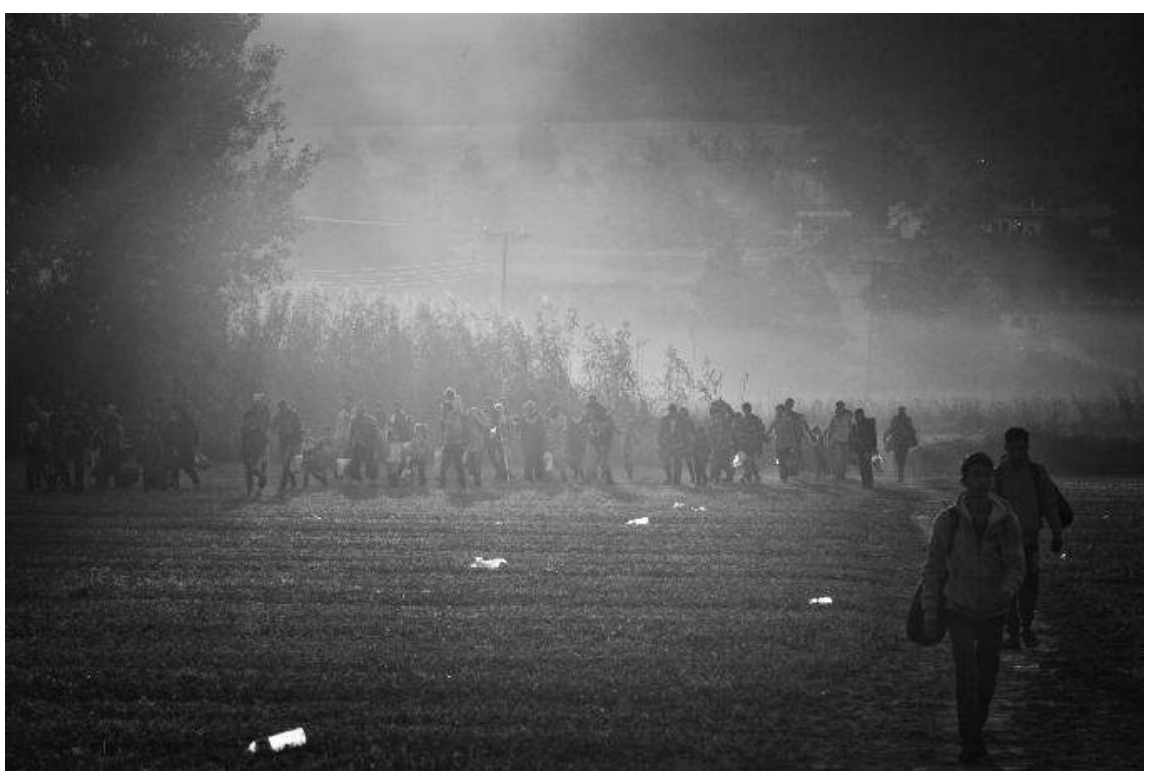

Idomeni : Des migrants, qui viennent d'arriver en Grèce, se dirigent vers la frontière gréco-macédonienne, alors que le soleil se lève, le 5 septembre 2015. Plus de 230000 réfugiés et migrants sont arrivés par voie maritime en Grèce au cours de 2015, contre 17500 durant la même période en 2014, déclara le ministre de la Marine.

(c) AFP PHOTO / LOUISA GOULIAMAKI

\section{- A. T. : Comment te sentais-tu à Idomeni?}

- L.G. : J'étais profondément bouleversée par leur souffrance. Les conditions de vie y étaient immondes, rien n'était suffisant, ni les services ni le ravitaillement, les associations avaient beau essayer, elles étaient débordées par le nombre de personnes présentes sur le lieu. Mais les gens ne se sentaient pas misérables, ils espéraient tous pouvoir traverser la frontière. Il est révélateur que, malgré cet énorme rassemblement sauvage, il n'y avait pas d'incidents.

J'ai été aussi frappée par l'attitude des policiers. Ils étaient très émus, ils étaient tout le temps en contact avec les enfants et les familles pour leur venir en aide. Le plus souvent, ils étaient là depuis trois mois, il leur était impossible 
de faire preuve de violence envers ces personnes, ils se demandaient ce qu'il adviendrait de toutes ces familles, ils se préoccupaient du sort des enfants. Je me rappelle d'un policier qui aidait une femme en transportant du bois à sa place, il me voit en train de le prendre en photo, il se fige et laisse tomber le bois, je lui présente mes excuses et je m'en vais immédiatement pour ne plus le déranger. Je n'ai jamais vu un tel comportement policier auparavant... bien évidemment, les unités anti-émeutes se comportaient autrement.

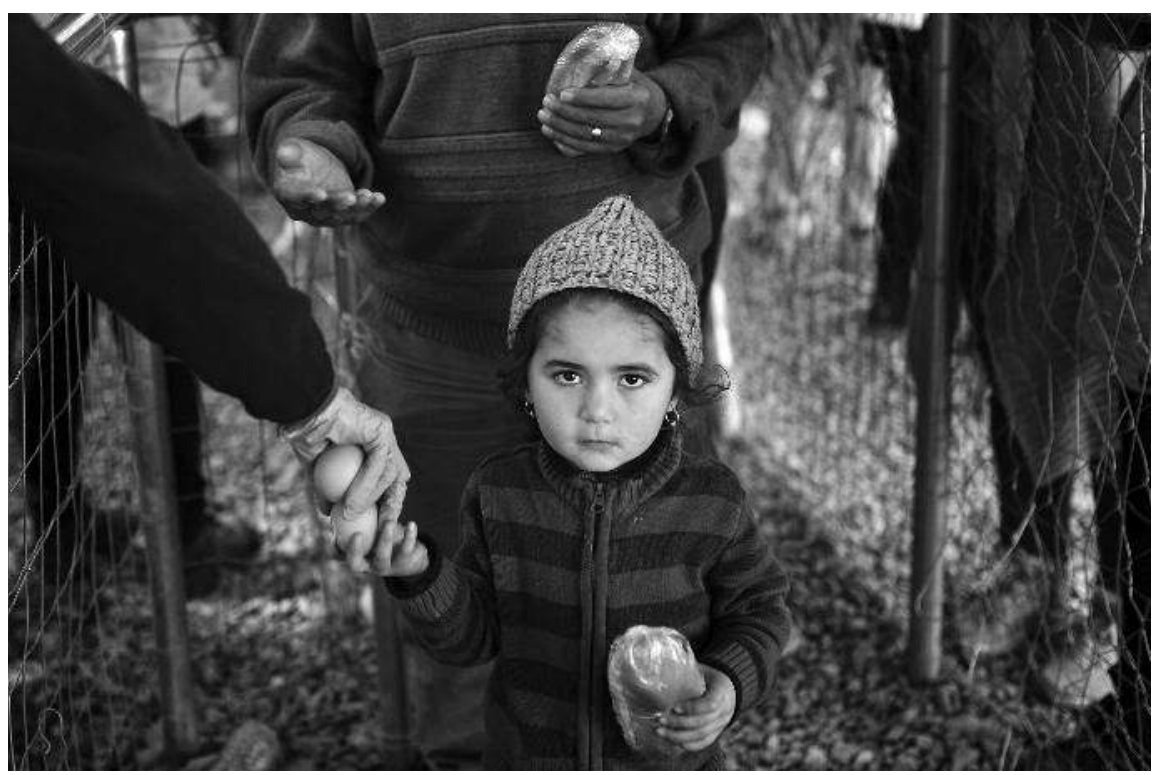

Une enfant reçoit son déjeuner dans le campement sauvage installé près du village frontalier d'Idomeni, le 2 mars 2016.

O AFP PHOTO / LOUISA GOULIAMAKI

- A. T. : Je crois qu'on touche ici à la sacralité de la famille en Grèce, d'autant plus que l'image de familles déracinées renvoie à des mémoires collectives, liées à l'arrivée de près d'un million et demi de réfugiés grecs en 1922. D'un autre côté, même si on est raciste, on a du mal à être agressif envers des réfugiés en transit. Ces étrangers ne soubaitant qu'aller ailleurs, ils ne peuvent constituer aucune "menace " pour le pays, donc on a tout intérêt à les aider à partir.

- L. G. : Tout à fait, certains me l'avaient dit ouvertement. C'est ainsi qu'ils les percevaient. En même temps, d'autres étaient prêts à les accueillir chez eux. Ils n'étaient pas tous pareils.

- A. T. : Tu étais là quand on a fermé définitivement la frontière, le 9 mars 
- L. G. : Oui. Peu avant, un groupe de réfugiés avait essayé de forcer le passage en cassant la porte qui menait à la gare ferroviaire. La police macédonienne a chargé en utilisant des gaz lacrymogènes superpuissants, les plus puissants que j'aie jamais respirés durant toute ma carrière. Je n'ai aucun souvenir de ce que j'ai fait pendant les deux minutes qui ont suivi la charge policière, j'ai vu postérieurement que j'avais tiré des photos, donc j'étais consciente. Je ne peux pas oublier le fait que, pour des raisons que j'ignore, le groupe était majoritairement composé de femmes et d'enfants. Quand la police a chargé, les hommes qui étaient en première ligne se sont dispersés et c'étaient les femmes et les enfants qui ont respiré les gaz lacrymogènes. Je vois encore leurs corps jonchant le sol, mi-évanouis.

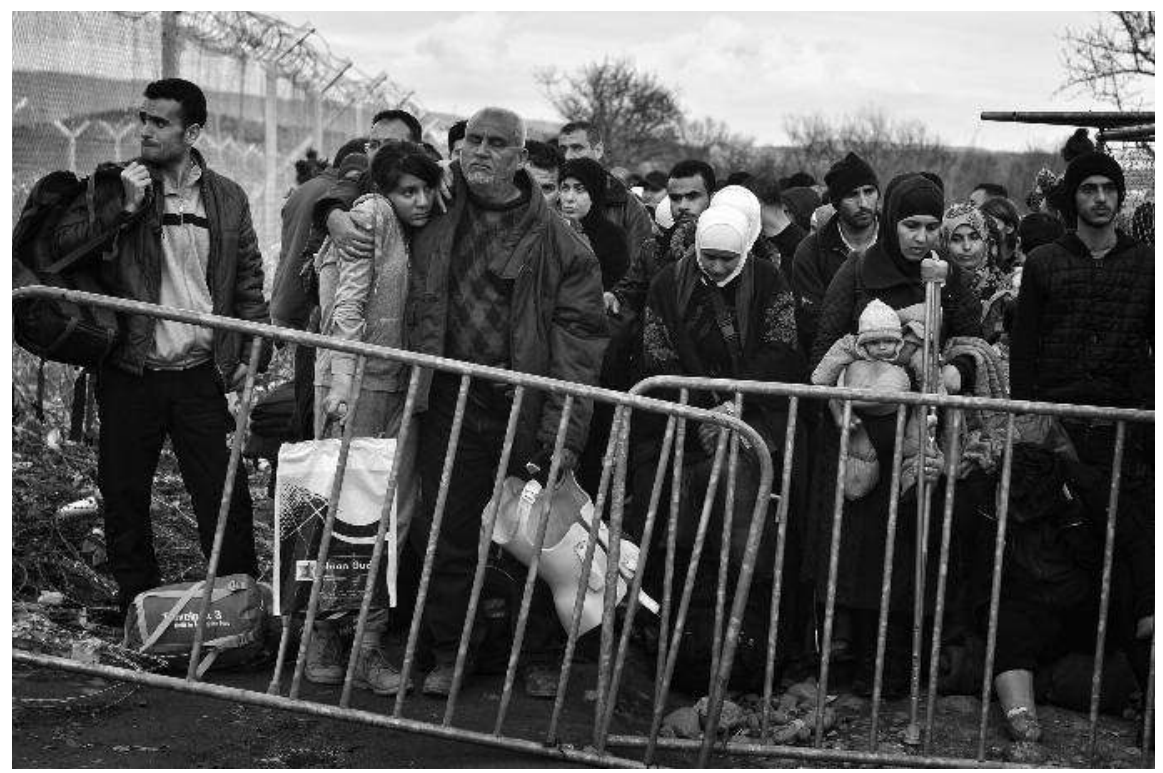

Des réfugiés attendent derrière des barrières à la frontière gréco-macédonienne, près du village grec d'Idomeni, le 29 février 2016, pour pouvoir entrer en Macédoine où se trouvent coincées des milliers de personnes. Alors que l'Autriche et les pays balkaniques limitent le nombre de migrants pouvant entrer sur leur territoire, les candidats au départ se bousculent le long de la frontière gréco-macédonienne et Athènes prévient qu'il pourrait y avoir près de 70000 personnes «piégées » le mois suivant.

(c) AFP PHOTO / LOUISA GOULIAMAKI

Quand l'accord UE-Turquie a été conclu, personne n'y a cru, personne ne croyait que les frontières avaient été définitivement fermées. Nous essayions de leur expliquer que la fermeture était définitive, que l'accord ne saurait être rapidement modifié car il s'agissait d'un accord européen et non pas d'un simple accord bilatéral. Certains en étaient convaincus et se dirigeaient vers les centres d'accueil qui étaient alors créés à cette fin. La majorité écrasante, tou- 
tefois, restait sur place soit en attendant la réouverture des frontières soit en essayant de traverser la frontière illégalement. Dans tous les cas de figure, ils n'étaient pas désespérés, loin de là.

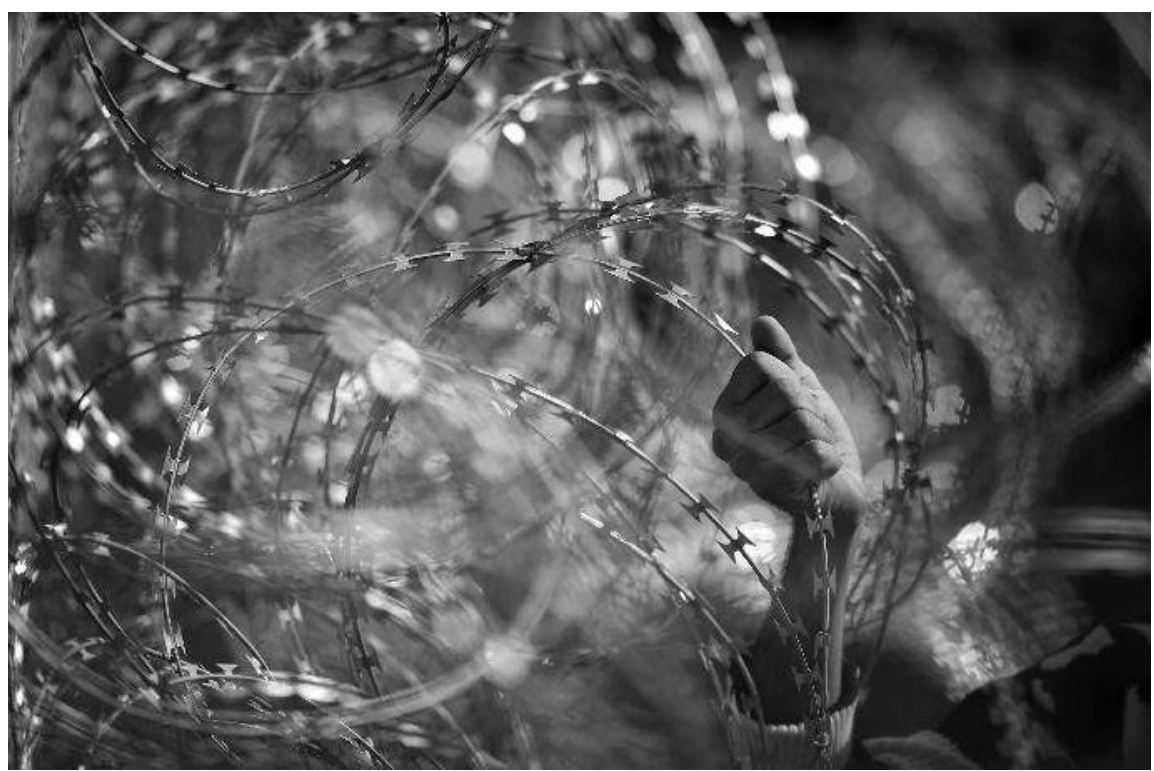

Un réfugié empoigne le fer barbelé du passage frontalier fermé, à la frontière gréco-macédonienne, près du village d'Idomeni, le 1er mars 2016.

(c) AFP PHOTO / LOUISA GOULIAMAKI

- A. T. : D'accord, mais toi, tu savais que la fermeture de la frontière était définitive.

- L. G. : Je parlais à tous ceux que je connaissais déjà, j'essayais de les convaincre de se diriger vers des centres d'accueil et de tenter, dans un deuxième temps, de poursuivre leur voyage vers l'Europe du nord grâce à la procédure de réunification familiale. Bref, j'étais devenue de facto leur conseiller juridique. Tout comme, plus tard, à l'île de Chios, où je conseillais beaucoup de réfugiés sur leurs droits et sur les stratégies à suivre. Les questions juridiques étaient si complexes que j'ai dû préalablement me former longuement auprès de juristes experts en la matière.

J'ai continué à les conseiller tout au long de l'été 2016, au Pirée, où se rassemblaient ceux qui finissaient par quitter Idomeni. J'y ai croisé de nombreuses familles que j'avais rencontrées à Idomeni, en février. Nous étions tous très émus au moment des retrouvailles, on s'embrassait, on se serrait dans les bras les uns des autres... Les autorités les avaient placés provisoirement au Pirée avant de les canaliser vers des centres d'accueil aux alentours. Même là, les réfugiés me demandaient quand les frontières ouvriraient-elles à nouveau - 
non pas si elles ouvriraient, mais quand ouvriraient-elles. On avait beau leur expliquer la situation, ils ne changeaient pas d'avis. Ils insistaient en nous disant qu'ils avaient des informations différentes, il se peut qu'ils aient été délibérément désinformés par des trafiquants, je n'en sais rien.

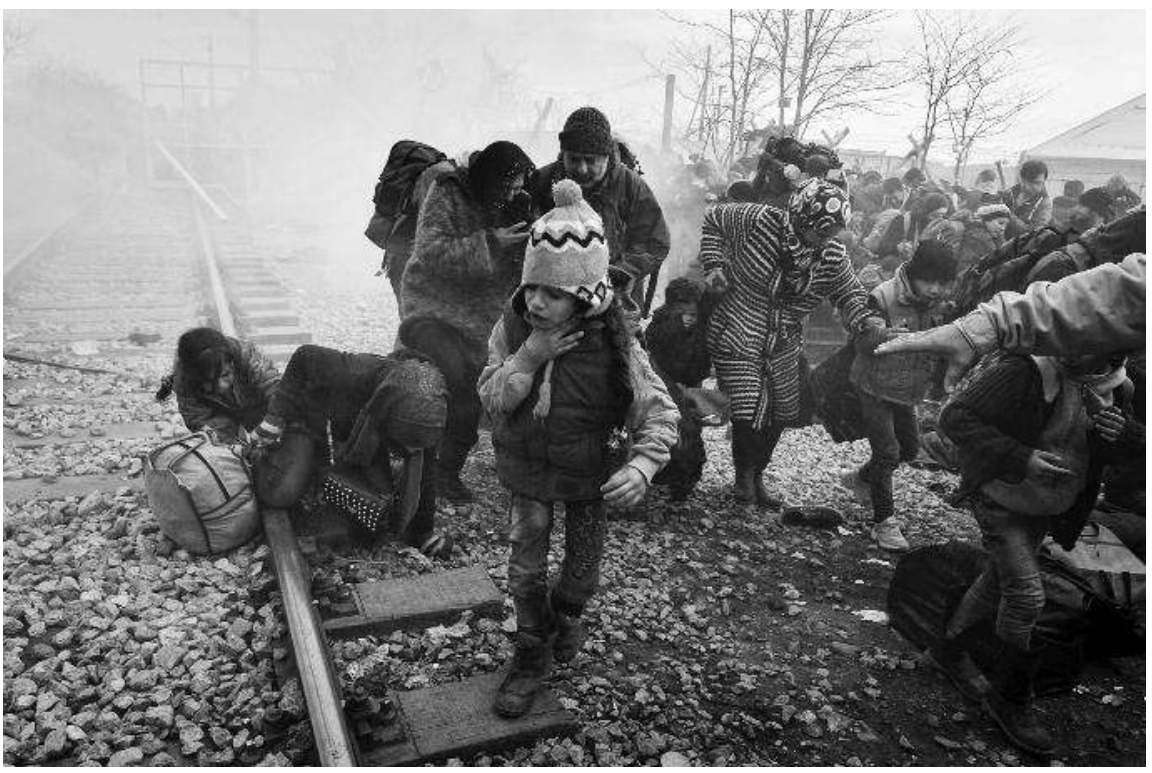

Une enfant tousse alors que des réfugiés et des migrants tentent d'échapper aux gaz lacrymogènes lancés par la police macédonienne contre des centaines de migrants irakiens et syriens qui avaient essayé de forcer le passage à la frontière gréco-macédonienne, à Idomeni, le 29 février 2016. Selon la police grecque, il y a plus de 6000 personnes entassées à la frontière suite à la décision de l'Autriche et des pays balkaniques de limiter le nombre de migrants pouvant entrer sur leur territoire.

(c) AFP PHOTO / LOUISA GOULIAMAKI

Je donnais mon numéro de téléphone à beaucoup de monde, en précisant toutefois que je ne pouvais pas les aider à quitter le pays illégalement. Je me rappelle d'un jeune Afghan, il m'a dit qu'il pouvait partir du port d'Igoumenitsa (port liant la Grèce avec l'Italie), mais on lui avait interdit de porter son passeport, des chaussures et de l'eau. L'interdiction d'eau m'avait inquiétée, je lui ai dit de ne pas y aller. Je pouvais comprendre l'interdiction de chaussures, les garde-frontières les leur enlèvent souvent ou ils frappent les réfugiés aux jambes, pour qu'ils ne puissent pas courir, mais comment expliquer l'interdiction d'eau ? D'autres jeunes, que je connaissais depuis Idomeni, m’ont dit qu'ils avaient déjà payé les trafiquants qui leur permettraient de partir. Je ne sais pas s'ils ont réussi à quitter le pays, j'ai perdu leurs traces. Comme ils changeaient tous leur téléphone portable en fonction du pays où ils se trouvaient, on perdait leur trace dès qu'ils passaient d'un pays à l'autre. Il n'y a pas de contact durable dans des conditions pareilles. Je ne sais pas ce qu'il est advenu de tous ces gens que j'ai connus. 


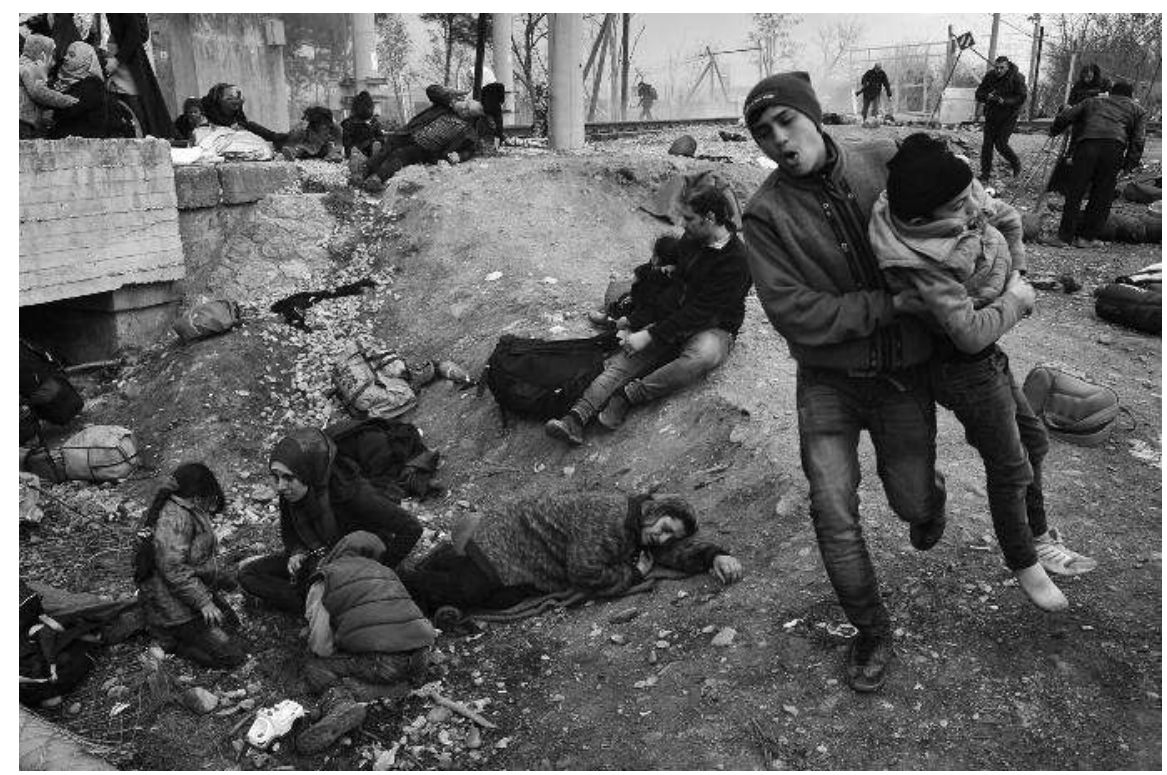

Un homme évacue un garçon, alors que d'autres réfugiés et migrants gisent sur le sol à cause des gaz lacrymogènes lancés par la police macédonienne contre des centaines de migrants irakiens et syriens qui avaient essayé de forcer le passage à la frontière gréco-macédonienne, à Idomeni, le 29 février 2016.

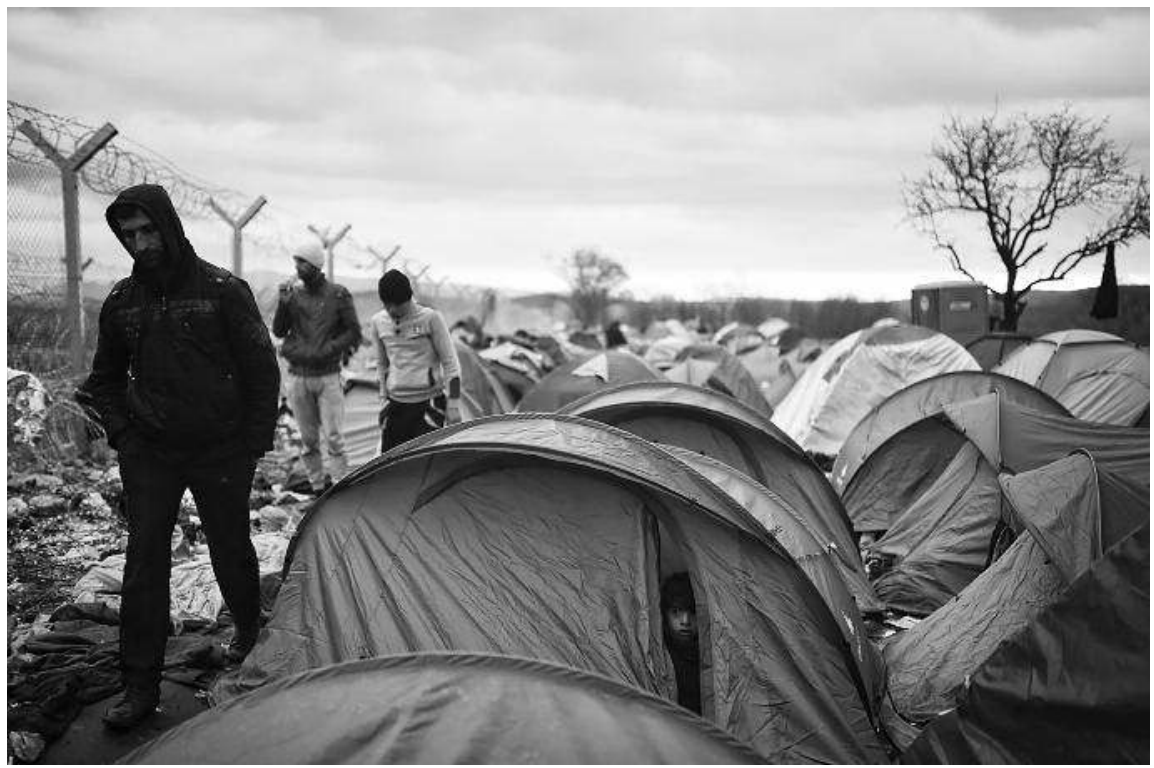

Des hommes marchent entre des tentes dressées tout au long de la clôture frontalière, dans le campement sauvage installé à la frontière gréco-macédonienne, près du village d'Idomeni où se trouvent coincés des milliers de réfugiés et de migrants, le 7 mars 2016.

(c) AFP PHOTO / LOUISA GOULIAMAKI 


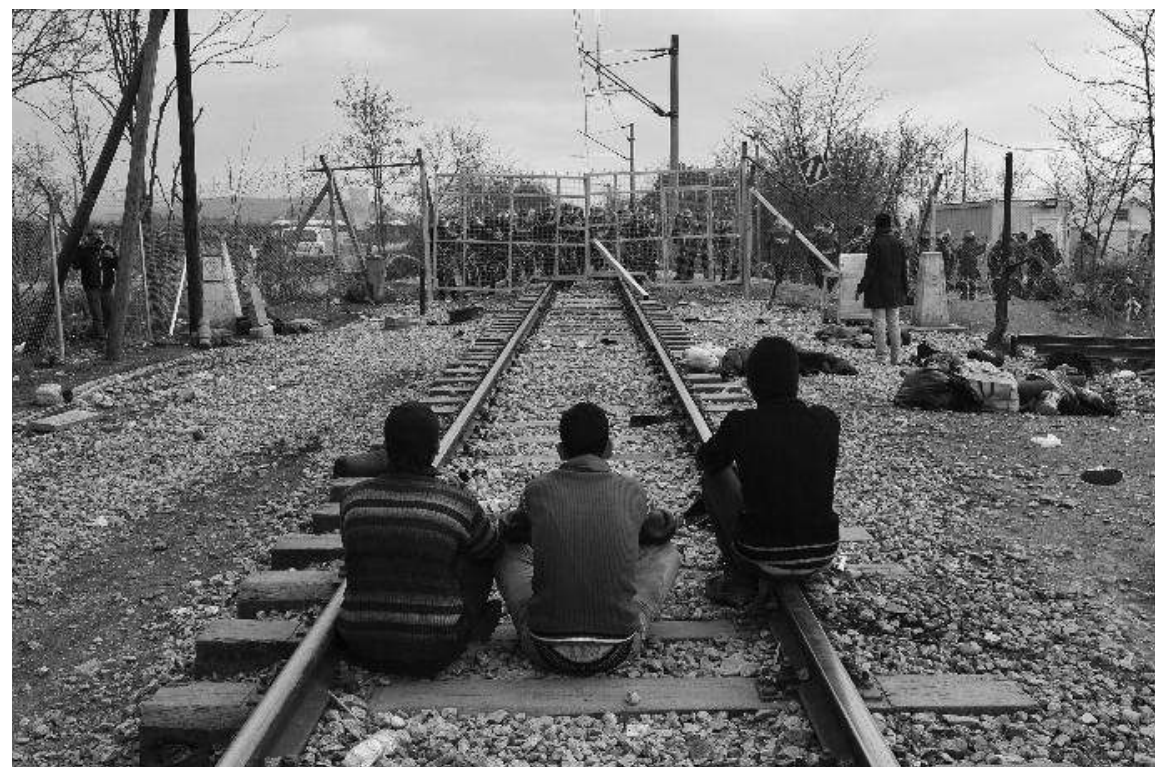

Des migrants sont assis sur les rails du train, le 29 février 2016, face au grillage gardé par la police macédonienne à la frontière gréco-macédonienne, près du village grec d'Idomeni, où se trouvent coincées plus de 7000 personnes. Alors que la colère monte à cause des restrictions de circulation imposées aux migrants, la police macédonienne a lancé des gaz lacrymogènes contre un groupe d'environ 300 Irakiens et Syriens qui, en forçant le cordon de sécurité de la police grecque, ont couru vers une voie ferrée entre les deux pays. Cette protestation a eu lieu plusieurs heures après que la Macédoine a autorisé 300 Irakiens et Syriens à traverser la frontière, avant de la fermer à nouveau.

(c) AFP PHOTO / LOUISA GOULIAMAKI

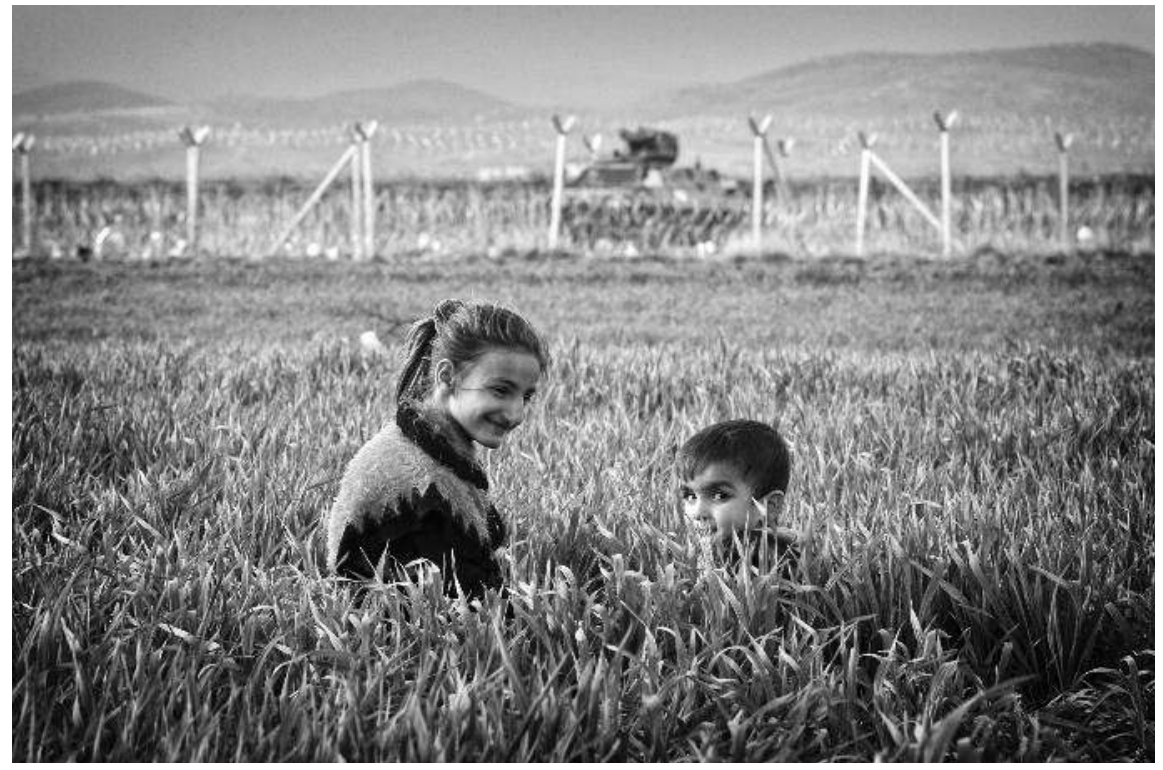




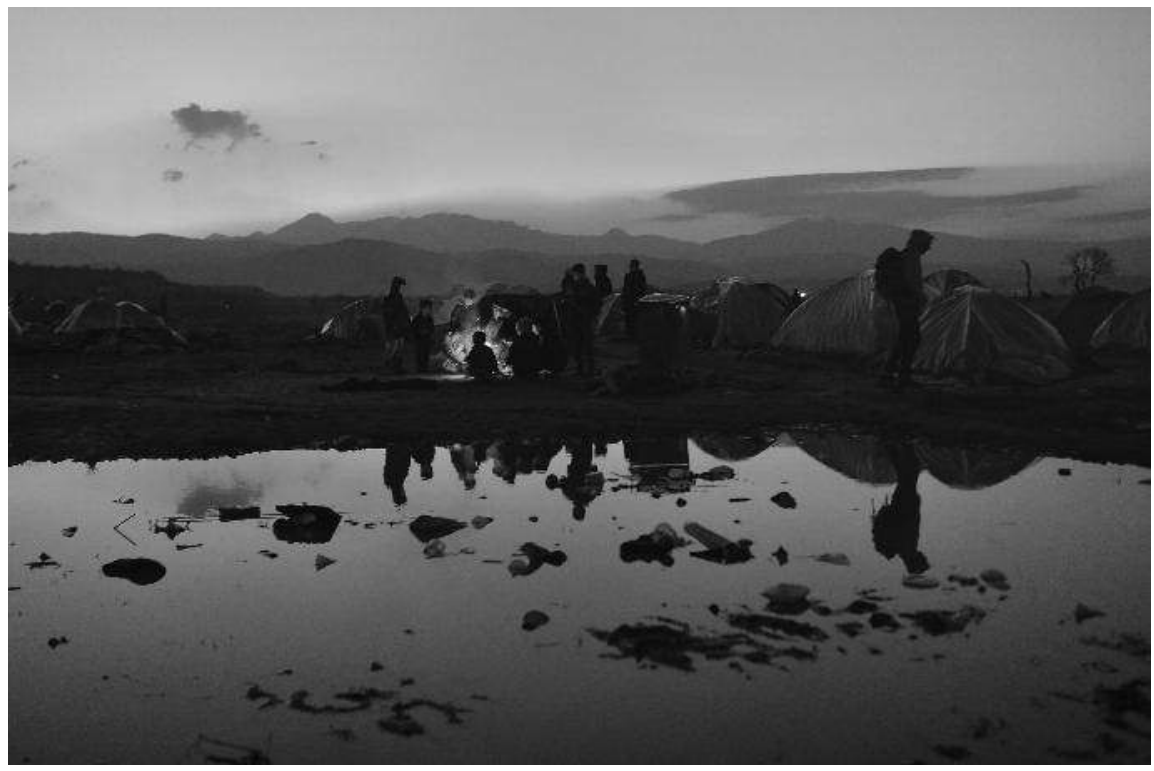

Des gens sont assis autour d'un feu, le 19 mars 2016, dans le campement sauvage installé à la frontière gréco-macédonienne, près du village d'Idomeni où se trouvent coincés des milliers de réfugiés et de migrants. Parmi les dizaines de milliers de réfugiés piégés dans des conditions exécrables suite à la fermeture des frontières des pays balkaniques, nombreux sont ceux qui se trouvent coincés près du village frontalier d'Idomeni.

(C) AFP PHOTO / LOUISA GOULIAMAKI

\section{Ci-contre :}

Idomeni : Des enfants jouent dans I'herbe près de la clôture frontalière à la frontière gréco-macédonienne, aux alentours du village d'Idomeni, où des milliers de réfugiés et de migrants se trouvent coincés, le 7 mars 2016. Le sommet UE-Turquie du 7 mars a été conclu sur la décision de soutenir la fermeture de la route des Balkans et d'insister auprès d'Ankara pour qu'elle reprenne les migrants économiques arrivant en Grèce. 


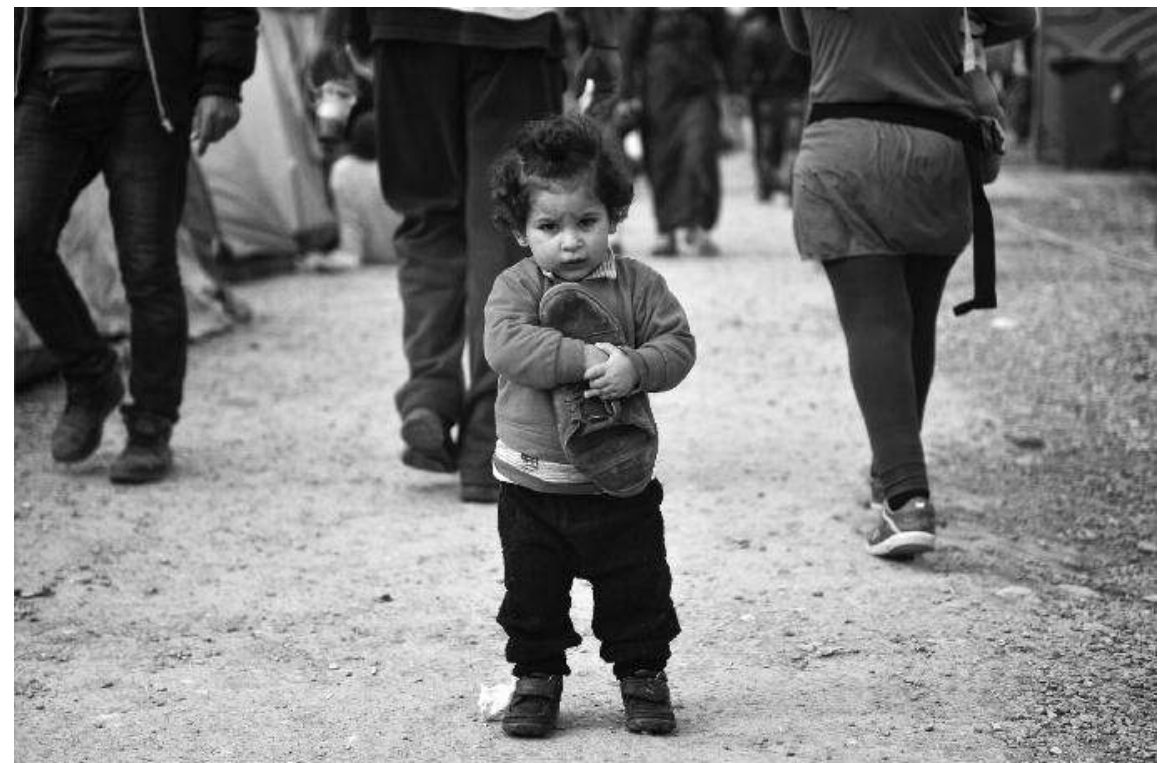

Une enfant tient une chaussure d'adulte entre les mains en attendant, avec d'autres réfugiés et migrants, de traverser la frontière gréco-macédonienne, le 3 mars 2016, près du village d'Idomeni où se trouvent coincées des milliers de personnes.

C AFP PHOTO / LOUISA GOULIAMAKI

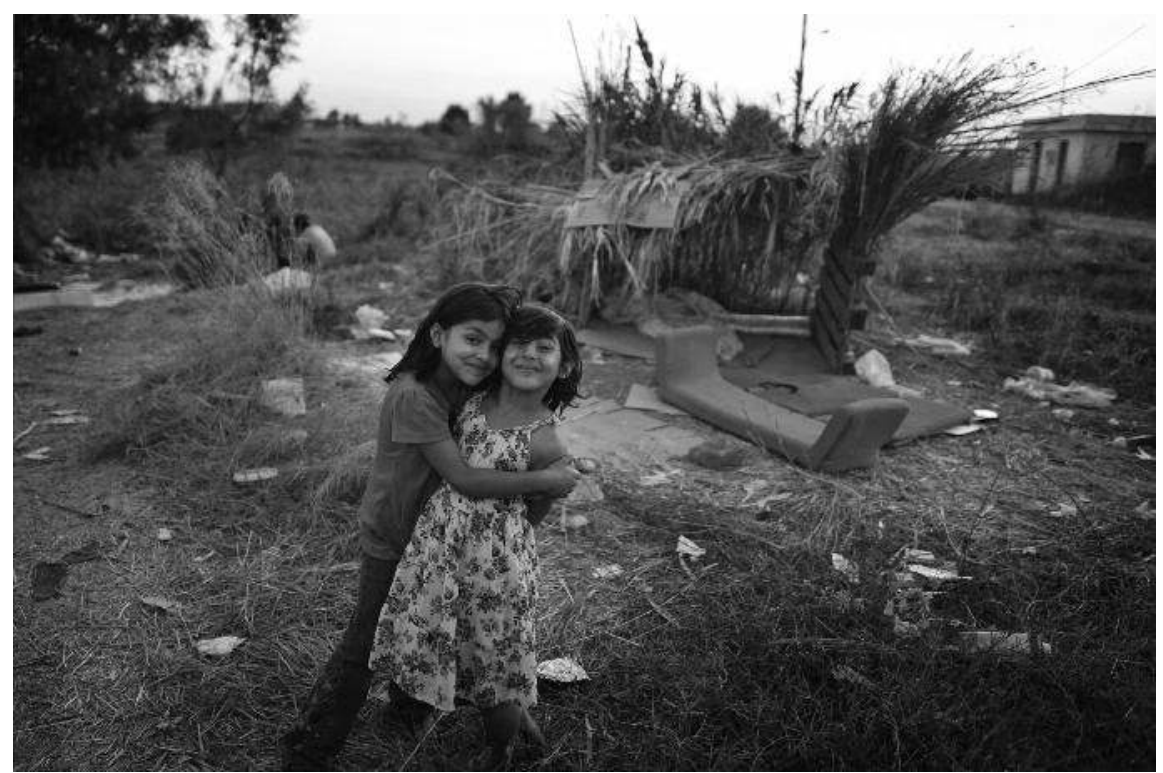

Des enfants migrants se tiennent dans les bras, le 16 août 2016, devant des abris de fortune construits en dehors de l'hôtel abandonné 'Captain Elias' où trouvent provisoirement refuge les migrants qui arrivent sur l'île de Kos.

(c) AFP PHOTO / LOUISA GOULIAMAKI 


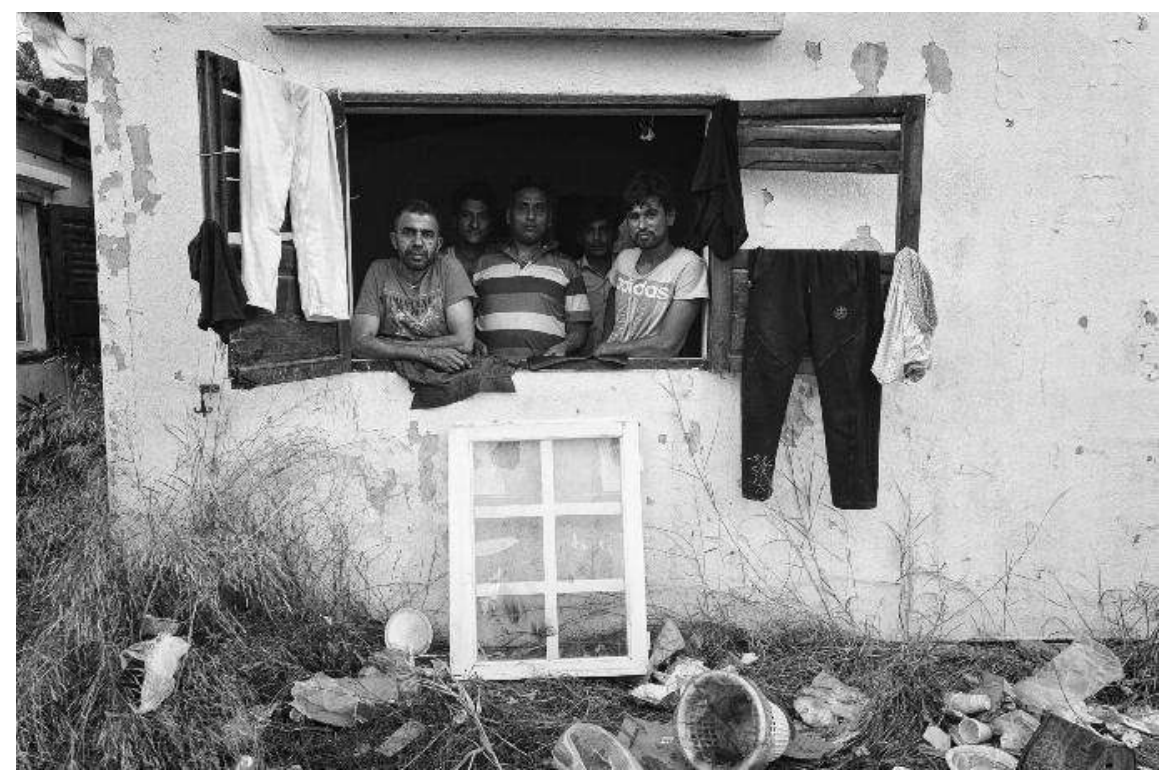

Des migrants regardent par la fenêtre de leur abri dans les locaux de l'hôtel abandonné 'Captain Elias' où trouvent provisoirement refuge les migrants qui arrivent sur l'île de Kos, le 16 août 2015. La carcasse de l'hôtel abandonné s'est transformée en abri de fortune pour de nombreux migrants fuyant la guerre et la pauvreté alors que l'Europe se trouve confrontée à la plus grave crise des réfugiés depuis des décennies. Des dizaines de personnes sont assises autour de la piscine vide, et d'autres sont couchées sur des matelas qui remplissent tout l'espace de la réception de l'hôtel, dont le jardin est plein de tentes et de cabanes faites en carton et en branches d'arbres.

() AFP PHOTO / LOUISA GOULIAMAKI

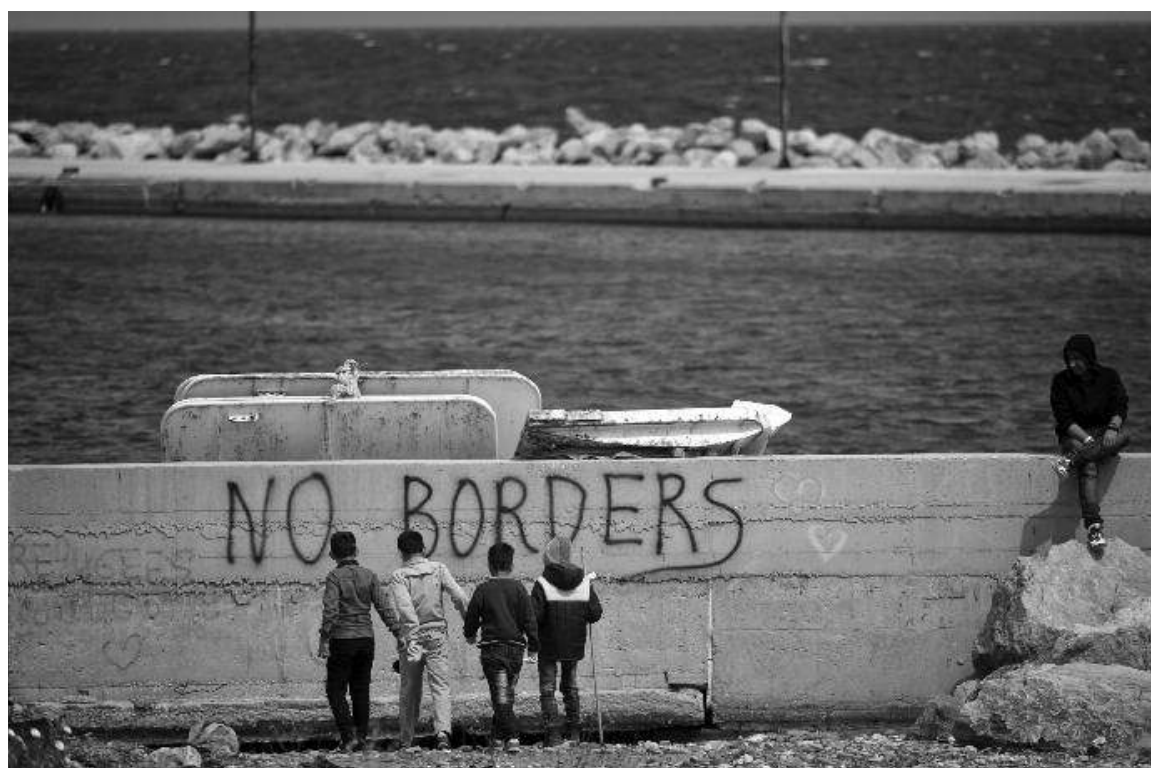


Page précédente :

Des enfants réfugiés jouent à la plage près du camp ouvert de Souda, aux alentours du port de Chios, le 3 avril 2016. Conformément à l'accord UE-Turquie, les réfugiés et les migrants arrivant en Grèce à partir du 20 mars seront maintenus dans des centres créés à cette fin sur cinq îles de la Mer Égée, dont l'île de Chios, et seront refoulés en Turquie si leurs demandes d'asile sont rejetées. Les retours devraient commencer le 4 avril.

(c) AFP PHOTO / LOUISA GOULIAMAKI

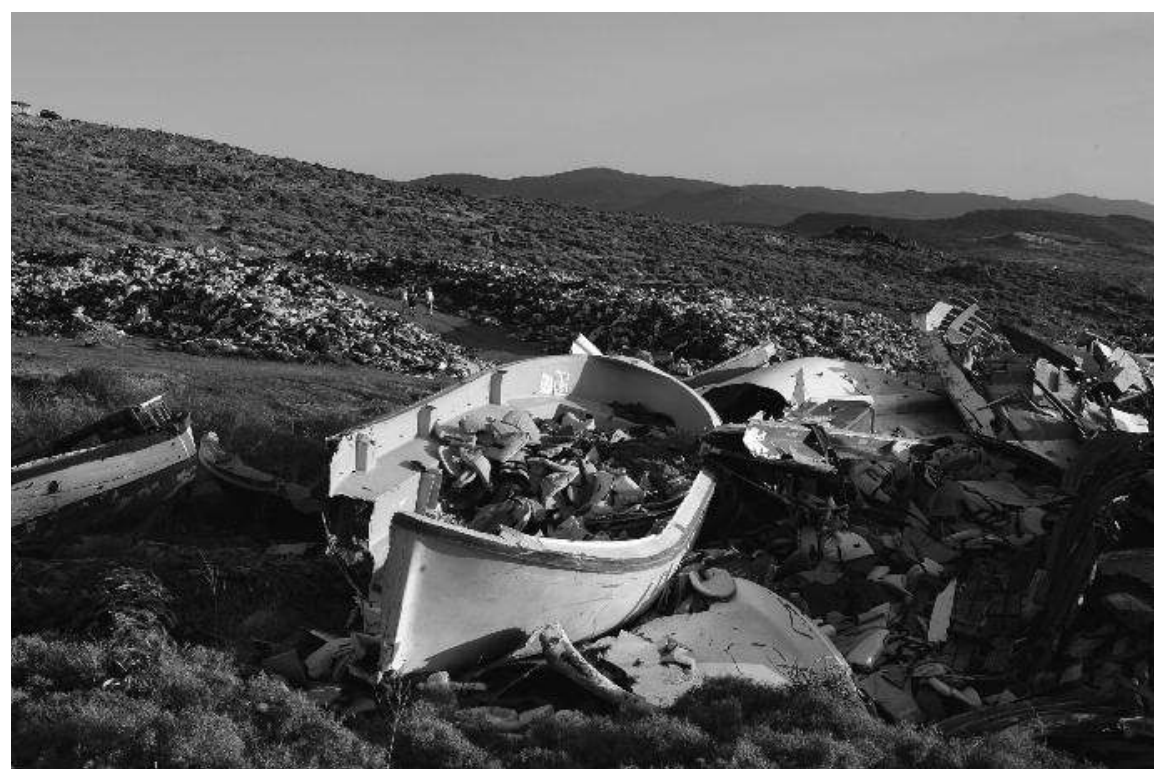

La décharge au-dessus du village de Molyvos, remplie de milliers de gilets de sauvetage et d'embarcations ramassées aux côtes de l'île, preuve de la crise des réfugiés de l'année dernière, est devenue une attraction touristique, le 18 juillet 2016. Quand une mer humaine a atteint les côtes rocheuses de leur île l'année dernière, les habitants de Lesbos ont accueilli les milliers de réfugiés émergeant de l'eau froide de la Mer Égée en leur offrant des couvertures et de la nourriture chaude. Mais cet élan d'hospitalité n'a eu aucun effet sur les revenus tant attendus en pleine saison touristique, car il paraît que beaucoup de touristes qui s'y rendaient habituellement ont été repoussés par les flux migratoires et ont choisi d'autres destinations de vacances. 


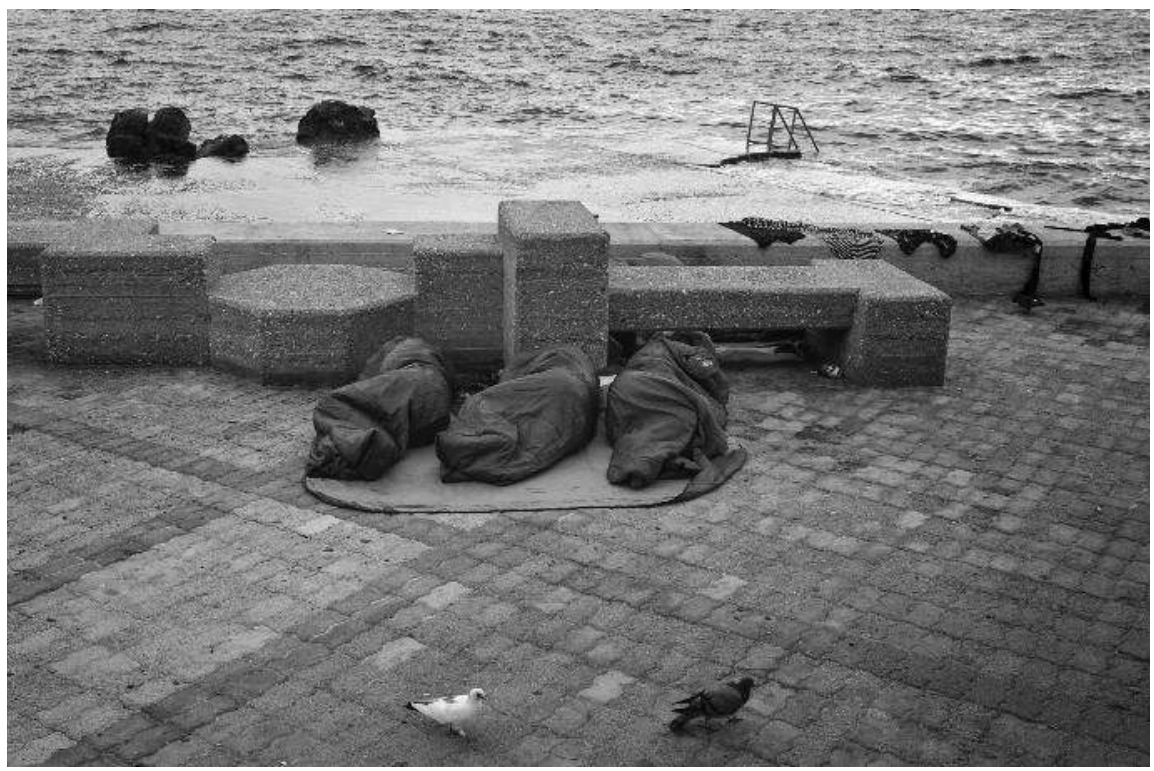

Des migrants, qui ont quitté le camp de Moria suite à un incendie, dorment au petit matin au port de Mytilène, sur l'île de Lesbos, le 21 septembre 2016. Des milliers de personnes ont pris la fuite le 19 septembre, quand des dizaines de tentes et d'abris dressés dans le camp de Moria, sur l'île de Lesbos, ont été incendiés suite à une rixe entre migrants de nationalités diverses. Certains migrants ont été canalisés vers Kara-tepé, le deuxième camp de l'île, alors que d'autres ont passé la nuit dans des églises, déclara Efi Latsoudi, une activiste des droits de l'homme qui, au début du mois, a été décorée pour son travail sur les réfugiés par l'Agence des Nations Unies pour les réfugiés.

(C) AFP PHOTO / LOUISA GOULIAMAKI 